\title{
Compreensões sobre a Atividade de Ensino Na EDUCAÇÃo SUPERIOR
}

\author{
UNDERSTANDING THE TEACHING ACTIVITY IN HIGHER EDUCATION
}

DOI: $\underline{\text { 10.23926/RPD.2526-2149.2020.v5.n3.p1980-1998.id904 }}$

\section{Tamini Wyzykowski Doutoranda em Educação nas Ciências (Unijuí) \\ Bolsista da Coordenação de Aperfeiçoamento de Pessoal de Nível Superior (Capes) tamini.wyzykowski@gmail.c om}

\section{Cátia Keske}

Doutoranda em Educação nas Ciências pela (Unijuí)

Professora do Instituto Federal Farroupilha (IFFar) catia.keske@iffarroupilha.ed u.br

\section{Sirlei Rigodanzo \\ Doutoranda em Educação nas Ciências (Unijuí) \\ Professora do Instituto Federal Farroupilha (IFFar) sirlei.koslowski@iffarroupil ha.edu.br}

\section{Cátia Maria Nehring}

Doutora em Educação pela Universidade Federal de Santa Catarina (UFSC) Professora da Unijuí catia@unijui.edu.br

\section{Maria Cristina \\ Pansera-de-Araújo Doutora em Genética e Biologia Molecular pela Universidade Federal do Rio Grande do Sul (UFRGS) Professora da Unijuí pansera@unijui.edu.br}

Resumo: $O$ artigo tem por objetivo compreender e discutir a atividade de ensino desenvolvida por professores no contexto da Educação Superior e suas implicações na significação de conhecimentos e para a constituição humana e profissional. Esta investigação é de natureza qualitativa e foi realizada a partir da Análise Textual Discursiva (ATD), em respostas atribuídas a um questionário semiestruturado respondido por 69 professores que atuavam na Educação Superior em 2019. A pesquisa enfatiza, a partir do referencial teórico, o ensino como a principal atividade do professor na Educação Superior. Os resultados produzidos apontam o protagonismo do aluno no processo de significação de conhecimentos. O trabalho destaca a importância de pensar-se a respeito da necessidade de transformações ou novas formas de prática profissional da docência nesse nível de ensino no contexto educacional brasileiro, com novas metodologias ou, até mesmo, com a reelaboração de currículos.

Palavras-chave: Constituição Humana. Constituição Profissional. Significação do Conhecimento.

\begin{abstract}
The article aims to understand and discuss the teaching activity developed by teachers in the context of Higher Education and its implications for the meaning of knowledge and for the human and professional constitution. This investigation is of a qualitative nature and was carried out from the Discursive Textual Analysis (DTA), in answers attributed to a semi-structured questionnaire answered by 69 teachers who worked in Higher Education in 2019. The research emphasizes, from the theoretical framework, teaching as the main activity of the teacher in Higher Education. Results produced point to the protagonism of the student in the process of signifying knowledge. The work highlights the importance of thinking about the need for transformations or new forms of professional teaching practice at this level of teaching in the brazilian educational context, with new methodologies or even with the reformulation of curriculum.
\end{abstract}

Keywords: Human Constitution. Professional Constitution. Meaning of Knowledge. 


\section{INTRODUÇÃOO}

O presente artigo tem o objetivo de discutir o papel da atividade de ensino na significação de conhecimentos e para a constituição humana e profissional no contexto da Educação Superior. Para tanto, a investigação parte da análise de respostas atribuídas a um questionário semiestruturado, respondido por 69 professores que atuavam na Educação Superior no ano de 2019.

Inicialmente, com apoio em autores que discorrem sobre a Educação Superior, como Gomes, Machado-Taylor e Saraiva (2018) e a Lei de Diretrizes e Bases da Educação Nacional - LDB n 9.394/96 (BRASIL, 2019), cabe demarcar que compreender aspectos da história e da legislação que organizam a Educação Superior brasileira auxilia a pensar a dimensão de ser professor nesse nível de ensino. A compreensão dos processos educativos como situados em um determinado espaço-tempo, desenvolvidos e vividos em um grupo social e em um período histórico, implica reconhecer os determinantes socioculturais e político-administrativos que os condicionam e constituem. Pensando no contexto brasileiro da Educação Superior, questionamentos relacionados às condições que favoreceram ou exigiram a oferta de formação para além da Educação Básica, bem como quanto aos objetivos e princípios que pautaram a criação das instituições de Educação Superior e aos desdobramentos sociais e econômicos, são essenciais para tal entendimento (GOMES; MACHADO-TAYLOR; SARAIVA, 2018).

Um contexto histórico, situado em um Estado que se autodenomina democrático e republicano como o Brasil, assim proclamado em 1889, é marcado por documentos normatizadores e legais quanto aos direitos e deveres dos seus cidadãos, a exemplo das diferentes versões de constituição federal até a Constituição da República Federativa do Brasil de 1988, bem como, no campo educacional, as três versões sobre as Diretrizes e Bases da Educação Nacional: Leis $n^{\circ} 4.024 / 61, \mathrm{n}^{\circ}$ 5.692/71 e a atual LDB n 9.394/96 (BRASIL, 2019). Apesar de nem todos terem caráter de representação de anseios populares e, contrariamente, muitos contemplarem necessidades de pequenos grupos, conforme relações de poder político e financeiro, o conjunto desses textos é consonante ao cenário do momento, sendo ele democrático ou não, pautando políticas públicas de Estado ou de governo. Aos docentes e gestores da Educação Superior não basta, porém, o conhecimento legal da sua organização; é preciso ver para além dos textos legais, sem permitir que estejam como objetivo primeiro e único, pois essa postura assegurará uma proposta legalista, adequada e em conformidade aos trâmites legais, sem, entretanto, garantir qualidade de formação profissional pautada pela produção científica (GOMES; MACHADO-TAYLOR; SARAIVA, 2018). 
Ao conhecer o passado e a introdução da Educação Superior no Brasil, podemos compreender aspectos da atualidade que, de uma oferta elitista para poucos, tencionou o ingresso de um número significativamente maior da população em cursos de Bacharelado, Tecnologia e Licenciatura, nas modalidades presencial e a distância. Por meio de um conhecimento dessa natureza, talvez seja possível entender as condições sob as quais a oferta de Educação Superior ocorreu, evidenciando que, nem sempre, acesso e qualidade têm sido equivalentes.

Reconhecer e analisar a história e a legislação são, sobretudo, ações que podem permitir clareza e objetividade sobre a continuidade e a manutenção de um sistema ou não, dada a possibilidade de se redefinirem caminhos. Mudanças, entretanto, acontecem por meio de proposições individuais ou coletivas. Na Educação Superior, os profissionais que nela atuam são sujeitos dela constitutivos com condições específicas e singulares para problematizar a atualidade, tanto de políticas públicas quanto de propostas pedagógicas. A consolidação e/ou alteração de suas práticas de ensino, pesquisa e extensão podem tencionar uma adequada política educacional (GOMES; MACHADO-TAYLOR; SARAIVA, 2018).

Para tanto, a ciência, quanto aos processos histórico e legal, é essencial para identificarmos mudanças necessárias e possíveis. É fundamental problematizar e refletir sobre as orientações e ações que condizem com a Educação Superior brasileira no século 21. Identificar e elaborar as alterações necessárias para tanto, podem pautar reivindicações políticas e proposições teórico-filosóficas ao encontro da expansão do acesso e da permanência em cursos superiores, fomentando o desenvolvimento científico, social e econômico brasileiro, de forma sustentável e contemporânea.

Ao professor e ao gestor do Ensino Superior importa, em especial, compreender que a oferta de educação nesse nível de ensino exige entendê-la como práxis $^{1}$, que não se modela, define ou transforma por documentos legais ou por reconhecimento da sua história (SCHÖN, 1992). É a práxis que muda ou se reorganiza conforme as demandas e as condições socioculturais e político-administrativas, e ante as quais se vê podendo contrapô-las ou de ratificá-las. Ao tomarmos consciência de que a Educação Superior precisa se constituir em um espaço formativo de aprendizagens e significação da cultura, é importante pensarmos nas

\footnotetext{
${ }^{1}$ Para Schön (1992, p. 91), "todo o processo tem envolvido uma reflexão coletiva sobre a prática do sistema escolar e tem tido grande impacto nos professores, [...] o que significa, então, tentar formar um professor para que ele se torne mais capaz de refletir na e sobre a sua prática?".
} 
atividades que os envolvidos no processo educativo devem primar por desenvolver, no caso a atividade de ensino pelo professor e a atividade de estudo pelo aluno.

Com base em Leontiev (1978), compreendemos "atividade" como correlata aos "processos que, realizando as relações do homem com o mundo, satisfazem uma necessidade especial [biológica, cultural ou histórica] correspondente a ele" (p. 165). A atividade social do professor é o ensino, e é por meio dela que ele se constitui humano e profissional, orientando o desenvolvimento intelectual de seus alunos. Uma atividade de ensino devidamente consciente corrobora a significação conceitual e estimula os alunos a desenvolver a atividade de estudo, permitindo aprendizagens e desenvolvimento cultural na Educação Superior. Assinalamos que significação, segundo Leontiev (1978, p. 94)

[...] é aquilo que num objeto ou fenômeno se descobre objetivamente num sistema de ligações, de interações e de relações objetivas. A significação é refletida e fixada na linguagem, o que lhe confere a sua instabilidade. Sob a forma de significações linguísticas, constitui o conteúdo da consciência social; entrando no conteúdo da consciência social, torna-se assim a "consciência real" dos indivíduos, objetivando em si o sentido subjetivo que o refletido tem para eles.

De acordo com o mesmo autor, podemos afirmar que uma atividade é uma série de ações e operações com motivo e objetivo comuns. A atividade do professor é ensinar de modo que os alunos tenham condições de aprender e, para tanto, estes precisam realizar a atividade de estudo de modo consciente. A aprendizagem em sala de aula é resultado das atividades de ensino e de estudo. Ao planejar sua prática, portanto, elencando metodologias ou instrumentos didáticos, o professor precisa perguntar-se: Existirá um motivo para que os alunos realizem as ações propostas?

Quando discutimos sobre Educação Superior reportamos, por vezes, a conhecimentos que tenham sincronia com as motivações e experiências profissionais dos estudantes do século 21. Nesse contexto, sendo a proposta das instituições de Educação Superior a produção e a sistematização de conhecimento para a sociedade, cabe questionar qual conhecimento se faz necessário para os profissionais do século 21. Ou, ainda, como a Educação Superior se movimenta diante do cenário atual, que está imerso em aparatos tecnológicos, primando pela necessidade de novas práticas de ensino? Segundo Marques (2014, p. 756),

a educação é parte da sociedade; qualquer que ela seja, tenha sido ou venha a ser. Para entendê-la é imprescindível mergulhar em sua história e nas especificidades que a tornaram o que é no presente. Mas para entender o seu sentido mais profundo, é preciso buscar este todo maior de que faz parte, a sociedade que a perpassa.

Essa proposição do autor provoca a pensar sobre o que antes era considerado conhecimento sacramentado dentro das bibliotecas das Universidades, e hoje é interpelado 
pelos meios de comunicação de massa, exigindo da docência um papel de intermediação durante os processos de apropriação de aprendizagens e desenvolvimento humano e cultural. Assim, a atividade de ensino na Educação Superior assume uma importante dimensão, devendo ser desenvolvida para atender à demanda formativa e profissional da nova geração.

Atentando para a expansão do acesso às informações, também cabe referir que o conhecimento problematizado nas Instituições de Educação Superior é mais do que a abordagem das informações geradas e disponíveis na rede virtual. $\mathrm{Na}$ atividade de ensino o professor precisa pensar em estratégias problematizadoras dos conceitos, estimulando os acadêmicos a elaborar as próprias respostas e pensar com criticidade, atribuindo sentidos para as informações e produzindo significados em relação aos conteúdos.

Junto disso, precisamos entender o que significa desenvolver uma atividade de ensino contextualizada com a realidade, o tempo e o espaço, em que o professor não é um transmissor linear de conhecimentos, mas um profissional que orienta os alunos a desenvolverem a atividade de estudo. Vale considerar a proposição apontada por Harari (2018, p. 319), de que "um bebê nascido hoje completará 30 anos em 2050. E, se tudo der certo, ele ainda estará vivo para testemunhar a entrada para o século 22." Isso nos conduz para o questionamento sistematizado pelo próprio autor: "de que tipo de habilidades ele ou ela precisará para conseguir um emprego, compreender o que está acontecendo a sua volta e percorrer o laboratório da vida?" (HARARI, 2018, p. 319).

Ao encontro dessas premissas e indagações, ressaltamos que importa investigar e produzir entendimentos relacionados à atividade de ensino desenvolvida por professores que atuam no contexto da Educação Superior, bem como suas implicações na significação de conhecimentos e na constituição humana e profissional. É nessa direção que se insere o presente estudo que propomos sistematizar neste artigo.

\section{Metodologia}

Esta investigação fundamenta-se na abordagem qualitativa de pesquisa em Educação (LÜDKE; ANDRÉ, 1986). Foram consultadas, como fonte de dados ou corpus textual de análise, respostas registradas em um questionário respondido por professores da Educação Superior. A pesquisa foi realizada no percurso da disciplina "Ensino Superior: Perspectivas das Ações do Professor", ofertada nos cursos de Mestrado e Doutorado do Programa de PósGraduação em Educação nas Ciências da Universidade Regional do Noroeste do Estado do Rio Grande do Sul (Unijuí). 
O referido questionário continha 23 perguntas e sua aplicação constituiu-se da seguinte dinâmica: cada estudante matriculado deveria desenvolvê-lo junto a professores em exercício em instituições de Educação Superior, independentemente da sua formação inicial e/ou atual área de atuação, desde que expressassem o desejo de responder e manifestassem autorização para utilizar as informações em produções acadêmicas.

Um total de 69 professores da Educação Superior, atuantes em instituições públicas, privadas ou comunitárias, participaram da pesquisa em 2019. As respostas de cada questionário foram inseridas em um banco de dados e tabuladas em planilha Excel. Para além da definição de categorias emergentes para e na análise dos dados, o todo de respostas retrata um grupo com maioria de professores do sexo feminino $(79,7 \%)$ e com atividade profissional voltada à educação - sem desenvolver outra atividade para além da docência (82,6\%). Nos Gráficos 1-4, apresentados nas Figuras 1 e 2, respectivamente, são sintetizadas faixa etária, formação acadêmica, regime de trabalho e tipo de Instituição de Ensino Superior (IES) de atuação (Centro Universitário, Faculdade, Instituto, Universidade).

Figura 1 - Gráfico 1: Faixa etária dos professores da Educação Superior, sujeitos da pesquisa

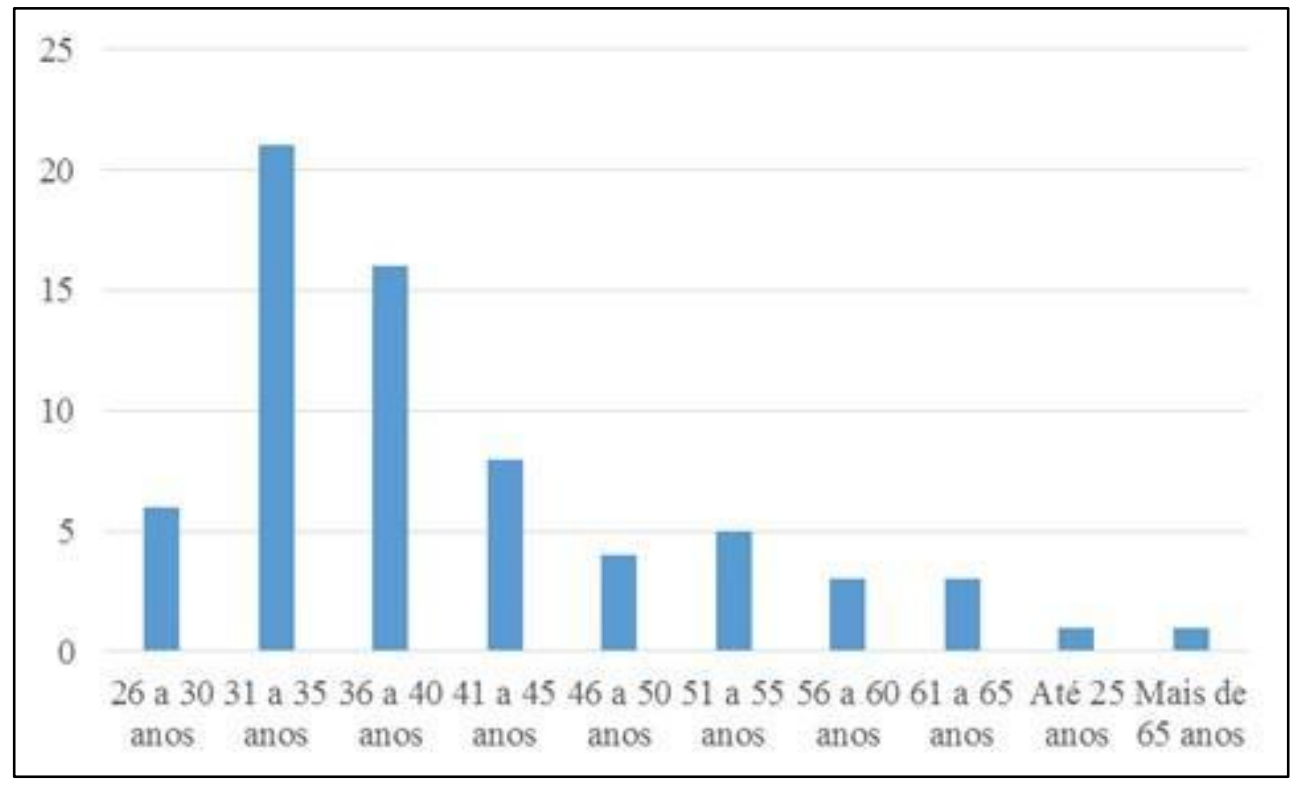

Fonte: Elaborada pelas autoras. 
Figura 2 - Gráficos 2, 3 e 4: Formação acadêmica, regime de trabalho e tipo de IES de atuação dos professores da Educação Superior

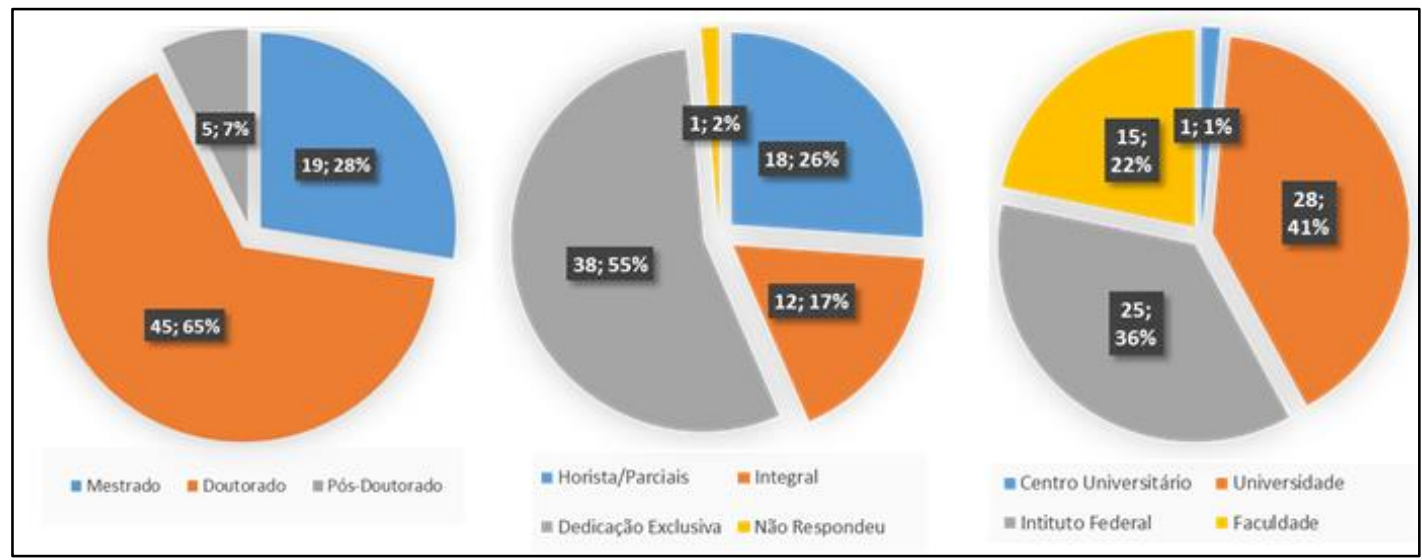

Fonte: Elaborada pelas autoras.

Independentemente se Centro Universitário, Universidade, Instituto Federal ou Faculdade (Figura 2), mais da metade das IES de atuação dos professores participantes da pesquisa são públicas (58\%) quanto à categoria administrativa, considerada a definição da Lei de Diretrizes e Bases da Educação Nacional (LDB) n 9.394/96 (BRASIL, 2019). Dentre as privadas, a maior parte é comunitária (28\%), sendo apenas $14 \%$ particular em sentido estrito , ou seja, 10 dos 69 professores atuam em IES privadas particulares. Vale destacar, ainda, que, assim como a característica "mais da metade do grupo de professores participantes da pesquisa possui regime de trabalho integral com dedicação exclusiva", também "mais da metade possui vínculo com IES pública" evidencia uma correlação entre docência na condição de servidor público e docência com dedicação exclusiva.

Nos Gráficos 5 e 6 (Figuras 3 e 4) são sistematizados, respectivamente, os dados que se referem ao itinerário profissional quanto ao tempo de exercício da docência e quanto à atuação nos diferentes níveis de ensino, com variação nas etapas do Ensino Superior.

Figura 3 - Gráfico 5: Trajetória profissional docente dos sujeitos da pesquisa

\begin{tabular}{|c|c|c|}
\hline Ensino Superior (Gr aduação) & 12 & \\
\hline Ensino Superior (Gr aduação e Pós-Graduação) & & 32 \\
\hline Educação Básica e Ensino Superior (Pós-Gr aduação) & 1 & \\
\hline Educação Básica e Ensino Superior (Graduação) & 13 & \\
\hline $\begin{array}{c}\text { Educ ação Básica e Ensino Superior (Graduação e Pós } \\
\text { Graduação) }\end{array}$ & 11 & \\
\hline
\end{tabular}

Fonte: Elaborada pelas autoras. 
Figura 4 - Gráfico 6: Tempo de atuação como professor dos sujeitos da pesquisa

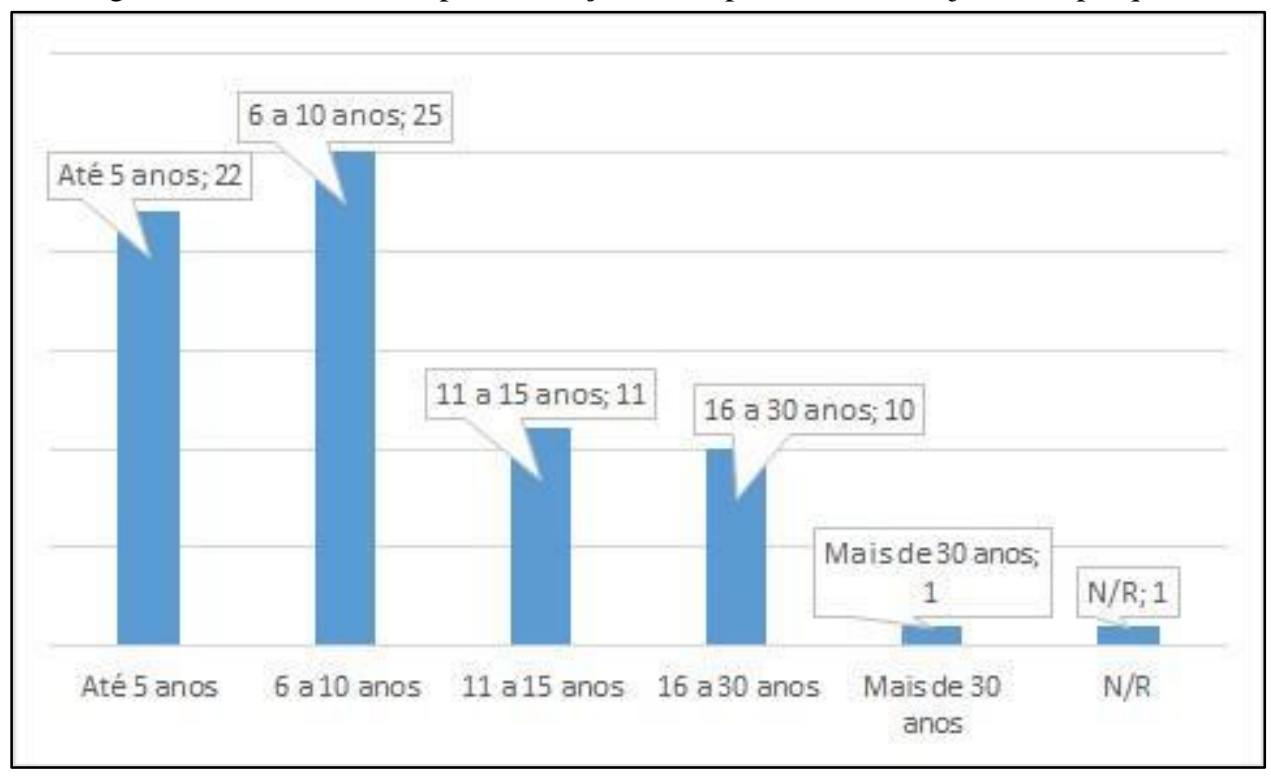

Fonte: Elaborada pelas autoras.

Para além do que é possível visualizar no Gráfico 6 (Figura 4), quanto ao tempo de atuação como professor vale acrescentar que a maior parte dos participantes tem menos de 10 anos de atuação (45 dos 69), e mais da metade (38 dos 69) desenvolve sua atividade profissional na mesma IES desde o início. Esse último número compõe o total de 44 professores, cuja atuação ocorreu somente no Ensino Superior, mesmo que na variação "somente na etapa Graduação" e nas "etapas Graduação e Pós-Graduação" (Gráfico 5 - Figura 3), dado que a condição para participação no estudo era "estar atuando na Educação Superior".

Com essa caracterização geral dos participantes da pesquisa, buscando a construção deste artigo, problematizamos respostas atribuídas a uma das questões abertas que compunha o questionário: Como você compreende a atividade de ensino na sua atuação na Educação Superior? Sobre isso nos ocupamos na sequência do texto.

Para descrever e procurar compreender os indicativos da questão, os dados foram organizados considerando os pressupostos teóricos da Análise Textual Discursiva (ATD) propostos por Moraes e Galiazzi (2016). Os autores explicam que a ATD é um "processo de desconstrução, seguido de reconstrução, de um conjunto de materiais linguísticos e discursivos", com o propósito de descrevê-los, interpretá-los e produzir, a partir disso, "novos entendimentos sobre os fenômenos e discursos investigados" (MORAES; GALIAZZI, 2016, p. 112). Assim, a ATD nas pesquisas qualitativas pode ser definida

como um processo auto-organizado de construção de compreensão em que novos entendimentos emergem de uma seqüência recursiva de três componentes: desconstrução dos textos do corpus, a unitarização; estabelecimento de relações entre os elementos unitários, a categorização; o captar do novo emergente em que a nova 
compreensão é comunicada e validada. Esse processo em seu todo pode ser comparado com uma tempestade de luz. O processo analítico consiste em criar as condições de formação dessa tempestade em que, emergindo do meio caótico e desordenado, formam-se flashes fugazes de raios de luz iluminando os fenômenos investigados, que possibilitam, por meio de um esforço de comunicação intenso, expressar novas compreensões atingidas ao longo da análise (MORAES, 2003, p. 192).

Nessa perspectiva, desenvolvemos o processo de ATD para interpretação, construção de categorias e problematização de resultados, uma vez que os sujeitos da pesquisa autorizaram a divulgação das informações registradas no questionário e que a Resolução nº 510/2016, do Conselho Nacional de Saúde (CNS), cuja redação trata das questões éticas envolvidas em pesquisas das diferentes áreas do conhecimento, foi observada (BRASIL, 2016). Por essa razão, as manifestações dos professores da Educação Superior, apresentadas neste texto, observaram a designação das respostas de cada questionário pelos termos P1, P2, P3 até o P69, a fim de manter o anonimato dos participantes envolvidos e a autoria dos excertos, sendo "P" a representação de professor. Na escrita, os excertos de respostas do questionário são exibidos com destaque entre aspas e grifados em itálico.

\section{ANÁliSe E DiscuSSÃo dOS RESUltados}

$\mathrm{Na}$ sistematização da pesquisa selecionamos alguns excertos de manifestações mais relevantes para a discussão proposta. Nas respostas registradas pelos professores, foi possível identificar e construir, pelo menos, duas categorias relacionadas à atividade de ensino na Educação Superior, que, a seguir, serão socializadas: (a) significação do conhecimento; e (b) constituição humana e profissional.

\subsection{A SignifiCaÇão do CONHECIMENTO Na EdUCAÇÃo SUPERIOR}

Nas manifestações dos professores participantes, referentes à atividade de ensino na Educação Superior, foi possível identificar que a (a) significação do conhecimento é um elemento essencial. O ensino, na concepção de P60, é "uma atividade que deve proporcionar a construção do conhecimento por parte do discente", ou, ainda, conforme P19, "proporcionar a a aluno o protagonismo na apreensão do saber, relacionando muito a prática e teoria em sala de aula". Podemos depreender que os professores envolvidos nesta investigação têm clareza do seu papel social, o que dá sentido à existência da profissão docente em qualquer nível, ou seja, ensinar de modo que os estudantes tenham condições de aprender. 
As respostas indicam que a significação do conhecimento é um fator levado em consideração no desenvolvimento da atividade de ensino na Educação Superior. Tais impressões também aparecem imersas na descrição de P18:

Para mim, o ensino é a atividade primeira da profissão de professor. Ao ensinar, o professor tem a oportunidade de levar ao outro, o desconhecido, ou de esclarecer ao outro, um pouco mais do que este já sabe. Também, porque ao ensinar, o professor se descobre e se reinventa a cada aula. Aprende com os alunos sobre coisas novas e também a olhar com outros olhos para o que já conhece. Ao ensinar, é dado ao professor a oportunidade de fazer a diferença na vida dos sujeitos aprendizes, seja pelo seu exemplo, seja pelos seus ensinamentos.

Maldaner (2014, p. 39) frisa que "detalhes de um conteúdo, já esquecidos, serão facilmente retomados dos livros, de artigos científicos, hoje, da Internet”. Para ele, "o que os professores precisam entender é que as carências são de significações dos conhecimentos históricos e de como isso se realiza" (p. 39). Os pressupostos do autor provocam a reflexão sobre o quanto é complexo o trabalho docente na Educação Superior, pois, em qualquer um dos dois níveis de ensino - tratando-se do contexto da educação brasileira -, a relação professoraluno não traz por si só a garantia de aprendizagens e nem assegura a plena formação humana e profissional dos sujeitos que ocupam as instituições de ensino na condição de estudantes. Em outras palavras, não basta estar na Educação Superior, ser aluno de Educação Superior; é necessário dispor-se a nela aprender.

Vale lembrar, como bem explicam Vieira e Sforni (2010, p. 55), que "aprender um conceito não é apenas saber o seu conteúdo, mas também saber fazer uso dele como instrumento para pensar os objetos e fenômenos". Observando os dados do nosso contexto investigativo, P30 parece corroborar e complementar essas afirmações ao manifestar que:

A atividade de ensino me possibilita, por meio dos conteúdos/temáticas/conceitos previstos nas ementas dos componentes curriculares, contribuir para que o acadêmico, de um lado, problematize a realidade, e de outro, contextualize o conhecimento na realidade vivida. Também possibilita, pela minha interação com o acadêmico, mediada pelo conhecimento, desenvolver pensamento crítico e reflexivo.

Gauthier et al. (2013, p. 349) propõem que "ensinar é necessariamente entrar em relação com o outro para transformá-lo, é julgar em contexto, é confrontar-se com o caráter contingente da interação social”. A partir das relações que se estabelecem na atividade de ensino, o professor "precisa ser capaz de perceber as dificuldades e necessidades dos alunos, além de constantemente refletir sobre a sua prática pedagógica e planejar atividades desafiadoras e motivadoras" que possibilitem a significação do conhecimento (ECCHELI, 2008, p. 211). Nessa direção, ao desenvolver a atividade de ensino na Educação Superior, "o professor deve 
utilizar metodologias que favoreçam tal construção, incluindo atividades de pesquisa, de forma que o aluno possa ser o sujeito da própria formação" (P60).

É de responsabilidade do professor planejar a aula, elegendo os instrumentos didáticos e metodologias de ensino capazes de mobilizar a significação conceitual. Nessa perspectiva, podemos depreender que o professor é um dos protagonistas na construção do conhecimento, e tem o papel de atuar como um intermediador dos processos de ensino e de aprendizagem, que se desencadeiam nos percursos formativos da Educação Superior. Nossas observações são corroboradas com o excerto registrado no questionário:

A atividade de ensino dentro da educação superior torna o professor mediador desse processo, cabendo a ele, garantir uma relação didática entre ensino $e$ aprendizagem. O processo passa a ser uma troca em que o professor transmite aos alunos o conhecimento adquirido durante seu processo de formação e o aluno contribui com suas próprias experiências tornando-se ativo, reflexivo e crítico além de participante do processo (P67).

A manifestação de P67 remete a pensar na relevância de se estabelecerem relações dialógicas entre professores e acadêmicos, a fim de estimular o desenvolvimento dos processos cognitivos, primando pela significação conceitual dos conteúdos problematizados nos espaços acadêmicos. Tardif (2002, p. 49-50) discorre que

\begin{abstract}
a atividade docente não é exercida sobre um objeto, sobre um fenômeno ou uma obra produzida. Ela é realizada concretamente numa rede de interações com outras pessoas, onde o humano é determinante e dominante e onde estão presentes símbolos, valores, sentimentos, atitudes, que são passíveis de interpretação e decisão, que possuem geralmente, um caráter de urgência. Elas exigem, portanto, dos professores, não um saber sobre um objeto de conhecimento nem um saber sobre uma prática e destinado principalmente à objetivá-la, mas a capacidade de se comportarem como sujeitos, como atores e de serem pessoas em interação com pessoas. Tal capacidade é geradora de certezas particulares, a mais importante das quais consiste na confirmação, pelo docente, de sua própria capacidade de ensinar e de atingir um bom desempenho na prática da profissão.
\end{abstract}

De acordo com Sabino (2012, p. 40), “o ser humano estabelece relações através de vínculos humanos e, a partir desses vínculos, estabelecidos em contexto sócio-histórico, é que vai construindo sua identidade, sua forma de ser e "estar no mundo"”. A interação é um elemento primordial no desencadeamento dos processos de ensino e de aprendizado, determinante na significação e apropriação de elementos conceituais (VIGOTSKI, 2001).

A função social do professor remete à atualização constante para atender o desafio de ensinar a heterogeneidade de sujeitos que ingressam nas nossas salas de aula. Harari (2018, p. 389) menciona que "no futuro próximo, algoritmos poderão completar esse processo, fazendo com que seja praticamente impossível que as pessoas observem a realidade por si mesmas". É importante pensar, quando falamos em formação, todavia, que ela necessita ir muito além do 
domínio conceitual dos conteúdos específicos ou técnicos das disciplinas cursadas. A formação continuada do professor precisa abranger as questões sociais e humanas, a construção do trabalho em equipe, a cooperação e a empatia, como elementos essenciais para desenvolver aprendizagens junto aos alunos.

Algumas abordagens da literatura reforçam a importância do trabalho do professor em todos os níveis de ensino, pautado no planejamento adequado à realidade e perpassando por todas as áreas do conhecimento, trabalhando de forma ampla conteúdos que são imprescindíveis para a constituição dos sujeitos. São tempos de renovação da Educação Superior, em que a tradição e a modernidade se unem em prol da formação para atender demandas do mundo globalizado, quando "o professor surge como o organizador desse processo, na medida em que lança a proposta e faz as perguntas, mas quem constrói ideias é o aluno" (BIANCHINI; ARRUDA; FIGLIOLO, 2015, p. 340).

\subsection{A CONSTITUIÇÃo HUMANA E PROFISSIONAL NA EDUCAÇÃo SUPERIOR}

$\mathrm{Na}$ análise das respostas do questionário, observamos que, no entendimento de parte dos professores, a atividade de ensino é um elemento determinante para a (b) constituição humana e profissional na Educação Superior, conforme pode ser observado nas expressões de P36:

Compreendo a atividade de ensino como um processo cujos seus significados ultrapassam a sala de aula e perduram da formação inicial para a continuada. $O$ processo de ensino e aprendizagem desenvolvido na universidade deve ser um processo de formação do ser humano, do profissional e do cidadão, isto é, de um indivíduo que desempenha vários papéis na sociedade. Considero a atividade de ensino e de aprendizagem complexos, que implica responsabilidades que nem sempre estão presentes na consciência do professor. Para tal, o professor deve sempre lembrar que ensinar e aprender é uma relação entre o que é conhecimento no sentido epistemológico e o que é o homem no sentido ontológico.

A manifestação de P36 revela possíveis contribuições da atividade de ensino nos contextos de Educação Superior. Na perspectiva de Soares e Cunha (2010, p. 30), "a docência no ensino superior é uma atividade complexa do ponto de vista político, social, intelectual, psicológico e pedagógico”. A atividade de ensino é determinante para a constituição cultural dos alunos, pois, segundo P27, ela é "fundamental para desenvolvimento da sociedade como um todo", e desencadeia o "processo de formação do ser humano, do profissional e do cidadão, de um indivíduo que desempenha vários papéis na sociedade" (P58).

Essas afirmações destacam a pertinência de refletir que "o que um sujeito social deixa de fazer, por não ter sido incluído na cultura de seu tempo, fará falta para todos e/ou diminui a qualidade de vida de todos, conforme defende Bakhtin” (MALDANER, 2014, p. 18). Seguindo a mesma linha de pensamento, Duarte (2011, p. 340) também adverte que "toda vez que o ser 
humano é impedido de apropriar-se daquilo que faça parte da riqueza do gênero humano, estamos perante um processo de alienação, um processo que impede a humanização desse indivíduo". As ideias dos autores direcionam para o entendimento da complexidade da Educação Superior em uma sociedade em constante transformação. Saviani (2007, p. 154) explica que

se a existência humana não é garantida pela natureza, não é uma dádiva natural, mas tem de ser produzida pelos próprios homens, sendo, pois, um produto do trabalho, isso significa que o homem não nasce homem. Ele forma-se homem. Ele não nasce sabendo produzir-se como homem. Ele necessita aprender a ser homem, precisa aprender a produzir sua própria existência. Portanto, a produção do homem é, ao mesmo tempo, a formação do homem, isto é, um processo educativo. A origem da educação coincide, então, com a origem do homem mesmo.

O ser humano é o resultado de uma construção histórica. Para Kant (2006, p. 11), “o homem é a única criatura que precisa ser educada", encontrando na educação a base para a formação humana. Sendo assim, a Educação Superior é um espaço educativo de promoção da cultura humana e do desenvolvimento das capacidades cognitivas dos sujeitos que ocupam os referidos contextos. Cabe a ela formar mais do que profissionais, constituindo seres humanos capazes de atuarem com autonomia, responsabilidade e criticidade no meio em que vivem. Para tanto, segundo Libâneo (2011), o ensino é o principal caminho, pois ele orienta o pensamento dos alunos. Na concepção desse autor, "aprender a pensar teoricamente é dominar os processos mentais pelos quais chegamos aos conceitos e às competências cognitivas, significa dominar os procedimentos metodológicos das ciências, para aprender pensar cientificamente" (LIBÂNEO, 2011, p. 189).

Além de formar novos profissionais, a Educação Superior também é um espaço constitutivo para os docentes que nela atuam. Os professores desenvolvem-se mais humanos e profissionalmente a partir da sua práxis (SCHÖN, 1992; TARDIF, 2002).

Nessa linha de pensamento, Nóvoa, ao retomar uma frase de Jennifer Nias (1991 apud Nóvoa, 2013, p. 15), trata especificamente da ideia que "o professor é a pessoa; e uma parte importante da pessoa é o professor". Nóvoa (2013) enfatiza que, na condição de professores, estamos no cerne do processo identitário da profissão docente, pois, mesmo em meio a processos de racionalização e uniformização, cada professor continuou sua maneira de ser professor. Para o autor,

a maneira como cada um de nós ensina está diretamente dependente daquilo que somos como pessoa quando exercemos o ensino [...]. Eis-nos de novo face à pessoa $\mathrm{e}$ ao profissional, ao ser e ao ensinar. Aqui estamos. Nós e a profissão. E as opções que cada um de nós tem de fazer como professor, as quais cruzam a nossa maneira de ser 
com a nossa maneira de ensinar e desvendam na nossa maneira de ensinar a nossa maneira de ser. É impossível separar o eu profissional do eu pessoal (p. 17).

A ênfase de Nóvoa (2013) na relação pessoal e profissional é por ele abordada também no conceito de um espaço entre-dois, entre a formação inicial do professor (sua Graduação e/ou Pós-Graduação) e a sua atuação em uma instituição de ensino, num entre-meio pelo e no qual "verdadeiramente, nos tornamos professores, que adquirimos uma pele profissional que se enxerta na nossa pele pessoal" (NÓVOA, 2019, p. 207). Trata-se de um espaço no qual, conforme Nóvoa (2019), a colegialidade, as decisões, as ações e o trabalho coletivo são valorizados, constituindo um entre-meio que potencializa a corresponsabilidade para a formação profissional e que protagoniza os saberes docentes.

Mormente nesse entre-meio é que o professor da Educação Superior exerce sua atividade profissional - a docência -, deixando importantes traços na formação de novos profissionais e na constituição humana desses sujeitos, e isso traz reflexos para a sociedade como um todo. Na convicção de P38:

no atual contexto da sociedade brasileira, onde o ensino passa por momento de extensa aflição devido a não existência do saber para onde se quer que a educação vá, é de extrema importância que os profissionais envolvidos e que fazem o dia a dia da educação no Brasil, mantenham-se mais do que nunca firmes em seu propósito de ensinar e multiplicar o saber. No Ensino Superior pode-se dizer que é a "última" instância de desenvolvimento do cidadão, onde ele pode finalmente abrir-se para o saber, logo a responsabilidade dos professores na Educação Superior é tão importante e responsável como qualquer outro momento do desenvolvimento do aluno/cidadão. Atividade que vai ao encontro aos sonhos de muitos alunos que conseguem com esforço fazer sua Faculdade; sendo assim, o fato de prepará-los ao mercado de trabalho é ao mesmo tempo estimulante e desafiador, pois muitos chegam de certa forma despreparados para uma Graduação.

Conforme destacado por P38, a atividade de ensino na Educação Superior possibilita direcionar os acadêmicos à apropriação de conhecimentos universais, perpassados ao longo da história, fundamentais para a compreensão da sociedade: questões culturais, econômicas, éticas, políticas, profissionais e tecnológicas que constituem o meio. Ela precisa estimular o pensamento crítico dos alunos ante as potencialidades e os problemas imersos nas práticas das diferentes profissões. Ademais, o próprio professor constitui-se permanentemente na docência conforme planeja, desenvolve, conduz, pensa e transforma suas ações nos processos educativos. Nesse sentido, P32 sublinha:

Na minha opinião o ensino é um dos aspectos fundamentais para a formação dos acadêmicos. Assim, é importante que o professor desenvolva nos alunos o interesse e uma postura ativa em busca do conhecimento e da sua formação profissional. Para mim, o ensino na atualidade manifesta-se como um desafio, uma vez que em meio a tantas inovações tecnológicas, o professor também precisa se desafiar a buscar o novo e oportunizar metodologias para que os alunos se envolvam (através da leitura, do estudo, da discussão e reflexão) e compreendam a importância daquele 
conhecimento para o seu fazer profissional. É através do ensino que os alunos conhecerão e aprenderão as bases teóricas para fundamentação da sua prática.

Para dar conta desse desafio, arriscamos responder que o professor precisa reconstruir constantemente sua prática educativa, transformando a atividade de ensino e transpondo os conhecimentos de modo que possam ser questionados, contextualizados e significados por seus alunos. Cunha (2018, p. 10) contribui conosco, para pensarmos esse contexto, ao enfatizar que o professor da Educação Superior necessita estar atento ao "assumir a docência como ação complexa", pois esta "requer saberes disciplinares, culturais, afetivos, éticos, metodológicos, psicológicos, sociológicos e políticos".

Dados do nosso contexto investigativo revelam que os professores da Educação Superior participantes têm consciência do seu papel social e também evidenciam, por vezes, a existência de possíveis debates acerca da relação de indissociabilidade entre ensino, pesquisa e extensão nas Instituições de Educação Superior, conforme menciona P5: “a atividade de ensino ocupa o princípio da minha atuação no Ensino Superior, pois em primeiro lugar sou professora (docente) para, na sequência, ser pesquisadora elou atuar em trabalhos de extensão".

A resposta de P5 orienta a refletir sobre a relação do ensino, da pesquisa e da extensão com a formação humana e profissional na Educação Superior. O corpus textual da investigação permite assinalar a relevância da relação de intercomplementaridade entre as dimensões constitutivas da prática docente na Educação Superior, o ensino, a pesquisa e a extensão, por meio das quais os professores significam e organizam seus modos de desenvolver, de ser e pensar a docência. Ao sistematizar e produzir conhecimentos por meio de uma ou de outra dimensão, o sujeito pode ressignificar as outras duas e, em um processo contínuo, aprende, ensina e volta a aprender na e com o ensino, a pesquisa e a extensão.

Com apoio em Sampaio e Freitas (2010), assinalamos que o ensino, a pesquisa e a extensão são três eixos estruturantes que possuem identidades e caracterizam a Universidade. De acordo com esses autores, os eixos precisam ser compreendidos como indissociáveis para que viabilizem a universidade a cumprir seu papel principal: formar profissionais com conhecimentos específicos e críticos em relação à historicidade e relevância social de sua profissão, capazes de agir com ética, comprometimento e cidadania nos diferentes espaços de atuação profissional. Com isso, podemos depreender que, para desenvolvê-los de modo indissociável, o professor precisa estar num constante processo de movimento e transformação em sua atuação profissional. Além disso, a universidade tem a missão de tentar contribuir para o desenvolvimento social e econômico da comunidade, "produzindo e socializando 
conhecimentos que dêem direito ao acesso à dignidade de vida de todas as pessoas" (SAMPAIO; FREITAS, 2010, p. 29).

Considerando que, por meio do ensino, o contexto acadêmico oportuniza aos graduandos a significação de conhecimentos de sua área de formação (SAMPAIO; FREITAS, 2010), as IES também devem primar pela produção de novos conhecimentos pelo desenvolvimento da pesquisa (vinculada a editais da instituição, com ou sem financiamento de Órgãos externos de fomento). Para melhor "formar" futuros profissionais, é igualmente importante desenvolver e socializar a produção acadêmica junto a outros segmentos da sociedade a partir da extensão, em que os projetos oportunizam a identificação das necessidades da comunidade de maneira dialógica, que podem e devem provocar estudos articulados que promovam a transformação da realidade ao vincular pesquisa, ensino e aprendizagem. Nessa dinâmica de complementaridade e indissociabilidade das três dimensões da Educação Superior, as IES são capazes de produzir conhecimentos (pesquisa) e formar profissionais qualificados (ensino) que atendam aos anseios e necessidades da sociedade (extensão) numa perspectiva dialógica.

Sampaio e Freitas (2010) também explicam que se a indissociabilidade de ensino, pesquisa e extensão é compreendida como uma necessidade de relevância institucional, ela deve ser articulada tanto em termos de princípios quanto de função na Universidade. Nesse sentido, segundo os mesmos autores, considerando o trabalho do professor no Ensino Superior, todas as funções e atividades que o docente se propor a desenvolver precisarão ser planejadas e articuladas atendendo e respeitando os princípios da indissociabilidade de ensino, pesquisa e extensão. Dentre essas funções e/ou atividades, estão incluídos o ensino em sala de aula, as práticas em laboratórios, os projetos de pesquisa, os projetos de extensão, os Trabalhos de Conclusão de Curso (TCC), os estágios supervisionados, dentre outras (SAMPAIO; FREITAS, 2010).

Essas constatações, expressas nos questionários e referenciais teóricos que orientaram nossas pretensões durante essa sistematização, tornam-se um sugestivo convite para pensarmos e continuarmos a investigar sobre tantos desafios que estão imersos na atividade docente dos professores que atuam na Educação Superior; desafios estes que, por vezes, vão além do trabalho em sala de aula e tencionam os professores a analisar sua práxis, transformar suas concepções pedagógicas e conceituais, direcionando, conscientemente, a atividade de ensino para a significação do conhecimento. A Educação Superior é um tempo e espaço de constituição 
humana e profissional que necessita primar pelo desenvolvimento de habilidades e do pensamento crítico, a fim de cumprir com seu papel social e promover a cultura.

\section{Algumas Considerações}

Finalizamos a escrita deste artigo com a consciência de que o estudo realizado não engloba todas as possíveis contribuições da atividade de ensino na Educação Superior, fundamental para a significação de conhecimentos e para a constituição humana e profissional. Esse assunto, no entanto, não se encerra aqui. A tecitura do trabalho foi apenas um exercício para pensar a atuação docente na Educação Superior, considerando algumas necessidades formativas e responsabilidades impostas a ela para o desenvolvimento mais pleno das profissões e da sociedade.

Compreendemos, a partir do referencial teórico, o ensino como a principal atividade psíquica do professor na Educação Superior; processo que auxilia no constituir-se humano e o valida como profissional na docência. Os indicativos feitos pelos sujeitos da pesquisa destacam o protagonismo do aluno no processo de significação do conhecimento, e remetem a pensar sobre a necessidade de transformações ou novas formas de (re)estruturação da docência nesse nível de ensino no contexto educacional brasileiro, com novas metodologias ou, até mesmo, a reelaboração de currículos.

Neste contexto, enfatizamos a importância da atividade de ensino na Educação Superior para a constituição dos sujeitos, acadêmicos e docentes, bem como no processo de formação para o mundo do trabalho. A atividade de ensino, desenvolvida pelo professor, é fator determinante na significação dos conhecimentos na Educação Superior e também se constitui na avaliação constante de sua prática para mais bem desenvolvê-la. Junto a isso, a interação entre professor e aluno torna-se substancial, pois a reflexão sobre a docência na Educação Superior tem evidenciado a necessidade de estabelecer a identidade do professor tanto no âmbito do ensino quanto da pesquisa e da extensão, se considerados indissociáveis no seu fazer profissional.

Compreendemos que a atividade de ensino na Educação Superior pode ser constantemente transformada em uma prática mais contextual, a partir da pedagogia de projetos, de metodologias ativas, por meio de elementos pedagógicos da sala de aula invertida ou com o apoio do pensamento computacional, dentre outros recursos. Estabelecer relações no processo de apropriação conceitual e inserir metodologias diversificadas, poderá favorecer a significação do conhecimento e a constituição humana e profissional na Educação Superior. Estes fatores 
são determinantes no desenvolvimento da práxis do professor e precisam ser problematizados na formação docente. Nisso reside a importância de pensar-se sobre as necessárias e possíveis transformações e/ou novas formas de prática profissional da docência nesse nível de ensino no contexto educacional brasileiro, até mesmo por meio da reconfiguração de currículos.

\section{REFERÊNCIAS}

BIANCHINI, Luciane Guimarães Batistella; ARRUDA, Renata Beloni de; FIGLIOLO, Gustavo Javier. Significação do conhecimento e sequência expandida: uma proposta criativa para trabalhar com textos literários. Nuances: Estudos sobre Educação, Presidente Prudente, SP, v. 26, n. 3, p. 323-342, 2015.

BRASIL. Conselho Nacional de Saúde: Resolução No 510/2016. Brasília: Ministério da Saúde, 2016.

BRASIL. LDB: Lei de Diretrizes e Bases da Educação Nacional. 3. ed. Brasília: Senado Federal, Coordenação de Edições Técnicas, 2019.

CUNHA, Maria Isabel da. Docência na educação superior: a professoralidade em construção. Educação, 41, n 1, 2018, p. 6-11.

DUARTE, Newton. Vigotski e o aprender a aprender: críticas às apropriações neoliberais e pós-modernas da teoria vigotskiana. Campinas, SP: Autores Associados, 2011.

ECCHELI, Simone Deperon. A motivação como prevenção da indisciplina. Educar, n. 32, p. 199-213, 2008.

GAUTHIER, Clermont et al. Por uma teoria da pedagogia. 3. ed. Ijuí: Editora Unijuí, 2013.

GOMES, Válter; MACHADO-TAYLOR, Maria de Lourdes; SARAIVA, Ernani Viana. O Ensino Superior no Brasil: breve histórico e caracterização. Ciência \& Trópico, Recife: Fundação Joaquim Nabuco, v. 42, n. 1, p. 106-129, 2018.

KANT, Immanuel. Sobre a Pedagogia. Trad. Francisco Cock Fontanella. 5. ed. Piracicaba, SP: Editora Unimep, 2006.

HARARI, Yuval Noah. 21 lições para o século 21. Tradução Paulo Geiger. São Paulo: Companhia das Letras, 2018.

LEONTIEV, Alexis Nikolaevich. O desenvolvimento do psiquismo. São Paulo, SP: Centauro, 1978.

LIBÂNEO, José Carlos. Conteúdos, formação de competências cognitivas e ensino com pesquisa: unindo ensino e modos de investigação. In: PIMENTA, Selma Garrido; ALMEIDA, Maria Isabel de (org.). Pedagogia universitária: caminhos para a formação de professores. São Paulo: Cortez, 2011.

LÜDKE, Menga; ANDRÉ, Marli. E. D. A. Pesquisa em educação: abordagens qualitativas. São Paulo: EPU, 1986. 
MALDANER, O. A. Formação de professores para um contexto de referência conhecido. In: NERY, Belmayr Knopki; MALDANER, Otavio Aloisio (org.). Formação de professores: compreensões em novos programas e ações. Ijuí: Editora Unijuí, 2014. p. 15-41.

MARQUES, Waldemar. Brasil, terra de contrastes. Avaliação, v. 19, n. 3, p. 749-771, 2014.

MORAES, Roque. Uma tempestade de luz: a compreensão possibilitada pela análise textual discursiva. Ciência e Educação, v. 9, n. 2, p. 191-211, 2003.

MORAES Roque; GALIAZZI, Maria do Carmo. Análise Textual Discursiva. 3. ed. revista e ampliada. Ijuí: Editora Unijuí, 2016. E-Book, 2020.

NÓVOA, António Sampaio da. Os professores e as histórias da sua vida. In: NÓVOA, António Sampaio da (org.). Vidas de professores. 2. ed. Porto Editora, 2013. p. 11-30. (Coleção ciências da educação).

NÓVOA, António Sampaio da. Entre a formação e a profissão: ensaio sobre o modo como nos tornamos professores. Currículo sem Fronteiras, v. 19, n. 1, p. 198-208, jan./abr. 2019.

SABINO, Simone. $\mathrm{O}$ afeto na prática pedagógica e na formação docente: uma presença silenciosa... São Paulo: Paulinas, 2012.

SAMPAIO, Jorge Hamilton; FREITAS, Marta Helena de. A indissociabilidade entre ensino, pesquisa e extensão. In: FREITAS, Lêda Gonçalves de; MARIZ, Ricardo Spindola; CUNHA FILHO, José Leão da (org.). Educação Superior: princípios, finalidades do ensino e formação continuada de professores. Brasília: Universa; Líber Livro, 2010.

SOARES, Sandra Regina; CUNHA, Maria Isabel. Formação do professor: a docência universitária em busca de legitimidade. Salvador: Edufba, 2010.

SAVIANI, Dermeval. Trabalho e educação: fundamentos ontológicos e históricos. Revista Brasileira de Educação, v. 12, n. 34, p. 152-180, jan./abr. 2007.

SCHÖN, Donald Alan. Formar professores como profissionais reflexivos. In: NÓVOA, A. (coord.). Os professores e a sua formação. Lisboa: Nova Enciclopédia, 1992.

TARDIF, Maurice. Saberes docentes e formação profissional. 5. ed. Petrópolis: Vozes, 2002.

VIEIRA, Vanize Aparecida Misael de Andrade; SFORNI, Marta Sueli de Faria. Avaliação da aprendizagem conceitual. Educar em Revista, n. especial 2, p. 45-58, 2010.

VIGOTSKI, Lev Semenovich. A construção do pensamento e da linguagem. São Paulo, SP: Martins Fontes, 2001.

Recebido em: 26 de agosto de 2020.

Aprovado em: 18 de novembro de 2020. 